\title{
LEI 13.709/18 - LEI GERAL DE PROTEÇÃO DE DADOS (LGPD) E OS REFLEXOS NO CAMPO DA PESQUISA CLÍNICA
}

Cláudia Mietlicki Nunes ${ }^{1}$

\begin{abstract}
RESUMO
O presente ensaio propõe a análise se serão necessárias adequações nos hospitais brasileiros que realizam pesquisa clínica a fim de atenderem as novas regras que passarão a valer com a entrada em vigor da Lei Geral de Proteção de Dados - LGPD (Lei 13.709/2018), que vigorará a partir de 2020. O artigo visa identificar, no âmbito da lei 13.709/18 os aspectos relevantes que interferem nos procedimentos adotados atualmente para coleta, armazenamento, transferência e manipulação dos dados dos pacientes/titular que participam de pesquisas clínicas, bem como identificar os possíveis conflitos entre as leis em vigor, os regulamentos administrativos e a LGPD. Por fim, pretende verificar se as novas exigências trazidas pela Lei Geral de Proteção de Dados irão impactar significativamente na realização de pesquisas clínicas podendo dificultar ou inviabilizar o seu desenvolvimento no país. A pesquisa foi realizada em fases distintas. Primeiro uma análise crítica sobre a nova legislação para evidenciar possíveis situações de conflito com as demais leis em vigor que versarem sobre a proteção de dados no âmbito das pesquisas clínicas. Num segundo momento, mediante a produção de conclusões de impacto junto à sociedade, para a propositura de ações que possam auxiliar a resolução de conflitos identificados em concreto.
\end{abstract}

Palavras-chave: Pesquisa clínica; Terapia gênica; Lei 13.709/18; Melhoramento Genético; Biotecnologia

\section{LAW 13.709/2018- GENERAL DATA PROTECTION LAW AND REFLECTIONS IN CLINICAL RESEARCH}

\begin{abstract}
This essay proposes the analysis of whether adjustments will be necessary in Brazilian hospitals that perform clinical research in order to comply with the new rules that will come into force with the entry into force of the General Data Protection Law - LGPD (Law 13.709/ 2018), which effective from 2020. The article aims to identify, within the scope of law $13.709 / 18$ the relevant aspects that interfere in the procedures currently adopted for the collection, storage, transfer and manipulation of patient / holder data participating in clinical research, as well as to identify possible conflicts between applicable laws, administrative regulations and the LGPD. Finally, it intends to verify if the new requirements brought by the General Data Protection Law will significantly impact the accomplishment of clinical researches that may hinder or make unfeasible its development in the country. The research was conducted in different phases. First a critical analysis of the new legislation to highlight possible situations of conflict with other existing laws on data protection in the context of clinical research. In a second moment, through the production of conclusions of impact with

\footnotetext{
${ }^{1}$ Mestranda em direito na Universidade La Salle - UNILASALLE-RS, bolsista com dedicação exclusiva pela CAPES.E-mail: cmn.direito@gmail.com.
} 
the society, for the proposition of actions that can help the resolution of conflicts identified in concrete.

Keywords: Clinical research; Gene therapy; Law 13.709 / 18; Enhancement; Biotechnology

\section{INTRODUÇÃO}

Recente notícia veiculada nos meios de comunicação chocaram o país ${ }^{2}$. Um cientista chinês chamou a atenção de profissionais das mais diversas áreas do conhecimento. Ele veio a público divulgar resultados de um experimento realizado no gene humano. $\mathrm{He}$ Jiankui afirma ter criado os primeiros bebês geneticamente modificados. Segundo ele, os pais se voluntariaram para o experimento. As gêmeas nasceram após uma fertilização in vitro e os embriões foram modificados antes de serem implantados no útero da mãe.

A notícia repercutiu negativamente no meio científico e médico, suscitando uma série de discussões de caráter ético e preocupações quanto ao impacto dos avanços tecnológicos nas diversas áreas, mas ainda mais no campo jurídico. Embora esse seja um caso que pouco se sabe, se o referido pesquisador possuia autorização para realizar os procedimentos de modificação genética. Pesquisas clínicas em seres humanos só são realizadas quando recebe previamente autorizações dos órgãos competentes.

Imprescíndivel destacar o papel fundamental que as pesquisas clínicas possuem tanto nacional quanto internacionalmente. Muitas doenças são curadas porque novos medicamentos e procedimentos são testados e aprovados.

Com o intuito de abordar o quanto as pesquisas clínicas são relevantes e necessitam que se tenha regulamento próprio, garantindo a sua manutenção, bem como a segurança para todos os participantes e envolvidos nas pesquisas, o presente ensaio irá abordar num primeiro momento as questões que digam respeito as novas tecnologias que estão desenvolvendo e aprimorando novas técnicas, a partir da e realizando modificações no gene humano. Abordando a conceituação de pesquisa clínica e sua regulamentação no ordenamento juridico.

2 Disponível em : https://g1.globo.com/ciencia-e-saude/noticia/2018/11/28/cientista-chinesque-anunciou-bebes-geneticamente-modificados-suspende-testes.ghtml, acessado em 26 de agosto de 2019. 
Num segundo momento será a vez de analisar o impacto das mudanças trazidas a partir da aprovação da Lei Geral de Proteção de Dados- Lei n ${ }^{\circ}$ 13.709/2018 com um olhar atendo para a situação dos hospitais que realizam pesquisas clínicas com pacientes e que portanto possuem bancos de dados que armazenam os dados dos pacientes, desde aqueles mais básicos, como telefone, endereço e dados de planos de saúde, aqueles que registram o acompanhamento do paciente a cada consulta, assim como os exames realizados, até os dados mais específicos como aqueles que registram as doenças a que são acometidos os pacientes, os dados genéticos, os medicamentos que faz uso e etc. A análise visa apontar quais serão os possíveis reflexos trazidos pela nova legislação no campo das pesquisas clínicas.

\section{Regulamentação da Pesquisa Clínica no Brasil.}

\subsection{Conceito}

A pesquisa clínica é de suma importância no desenvolvimento técnico e cientifico de avanços na área médica. A aprovação de novos medicamentos passa por diversas fases até a sua autorização e liberação no mercado de consumo ${ }^{3}$. Após passada a fase pré-clínica as demais fases são realizadas com seres humanos, como forma de testar a eficácia e possíveis reações adversas de medicamentos, da mesma forma ocorrerá quando se pretender instituir novas técnicas de cura.

A Resolução n 466/2012 do Conselho Nacional de Saúde, no inciso II.12 nos traz o conceito de pesquisa, qual seja:

"Processo formal e sistemático que visa à produção, ao avanço do conhecimento e/ou à obtenção de respostas para problemas mediante emprego de método cientifico".

De forma mais clara e objetiva é imprescindível trazer o conceito de pesquisa clínica:

"são estudos realizados com humanos para medir os parâmetros de segurança e eficácia de novos medicamentos, sendo essencial para a chegada

3 O artigo 12 da Lei 6.360/1976 estabelece que os medicamentos não serão industrializados e expostos antes de registrado no Ministério da Saúde, que só ocorrerá a partir da concessão da liberação pela ANVISA (art. 70, IX da Lei 9.782/1999). 
de novas alternativas terapêuticas no mercado. Estes ensaios são divididos em fases I, II,III e IV, de acordo com a quantidade de participantes e os objetivos específicos da cada etapa". ${ }^{4}$

Evidentes são os ganhos fruto das pesquisas clínicas, seja para a medicina, para comunidade acadêmica, seja de um modo geral para a população, uma vez que são a partir das pesquisas que surgem novos tratamentos, novos medicamentos, e novas técnicas, com intuito de possibilitar a cura para determinadas doenças.

Contudo a preocupação suscitada pela autorização de pesquisas clínicas diz respeito ao cuidado que se deve ter em relação ao participante de pesquisa que segundo a Resolução no 466/2012 do CNS é o indivíduo que, de forma esclarecida e voluntária, ou sob o esclarecimento e autorização de seu(s) responsável(eis) legal (is), aceita ser pesquisado. A participação deve ser de forma gratuita, ressalvadas as pesquisas clínicas de Fase I ou de bioequivalência (inciso II.10).

A Resolução $\mathrm{n}^{\circ} 466 / 2012$, traz diversas outras diretrizes a respeito do tema, como balizador para a prática de pesquisa clínica em seres humanos, mas evidente que muitas outras questões vão surgindo após a sua entrada em vigor e até mesmo em razão do desenvolvimento da própria pesquisa, que desperta necessidades antes desconhecidas.

Desta forma, a partir do desenvolvimento da pesquisa emerge que não só o campo da ciência médica evolua, mas principalmente a seara jurídica acompanhe tal evolução, permitindo que os estudos avancem, mas respeitando aos preceitos constitucionais de um país democrático de direito em que visa igualdade de tratamento a todos os cidadãos e, enquanto garantidor de direitos, que sejam resguardados aos pacientes/participantes da pesquisa e seus familiares às garantias quanto à saúde, integridade física, bem estar, autonomia, liberdade, respeito a moral, proteção de dados, dentre diversos outros direitos.

Novas tecnologias estão exigindo a adaptação aos avanços, que se tenham respostas mais rápidas no campo da pesquisa clínica, como é o caso da terapia gênica e do melhoramento genético. As técnicas já vêm sendo realizadas em experimentos em diversos países do mundo, mas muitos desses como o Brasil ainda não desenvolveram legislações

\footnotetext{
$4 \quad$ Conceito disponível em: http://portal.anvisa.gov.br/pesquisa-clinica. Acessado em 30 de agosto de 2019.
} 
capazes de autorizar ou barrar tal pesquisa.

Esse não é um problema que diga respeito à falta de vontade do Poder Público ou ausência de investimentos, a questão central é complexa, quando o assunto diz respeito à autorização de pesquisa clínica com seres humanos, se debate uma das questões mais sensíveis do direito, a vida, e que desencadeia que se observe muito outros direitos como por exemplo, a preservação da integridade física, e a necessidade de se resguardar os valores que compõe a dignidade humana e, portanto requer um debate amplo e alicerçado pelos princípios éticos e jurídicos.

\subsection{Regulamentação das Pesquisas Clínicas}

As Pesquisas Clínicas realizadas no Brasil não possuem uma lei específica que a regulamente. As diretrizes para a realização da pesquisa clínica têm como regulamento normas infralegais, de natureza administrativa, conforme vejamos

\footnotetext{
"Os ensaios clínicos no Brasil são regulados por normas infralegais, de natureza administrativa, emanada de órgão independentes, vinculados ao Ministério da Saúde e ao Sistema Único de Saúde (SUS), que compõem a administração direta e indireta da União Federal, respectivamente, o Conselho Nacional de Saúde, instância máxima de deliberação do SUS, e Agência Nacional de Vigilância Sanitária (ANVISA), autarquia federal, que editam normas de cunho ético-administrativo-procedimental. Os ensaios clínicos são também disciplinados por importantes normas deontológicas dos Conselhos Profissionais, tal como o Conselho Federal de Medicina, autarquia federal, que orientam a conduta dos médicos que realizam pesquisas". (PEREIRA, 2019, p. 6)
}

Em 2015 foi publicada pela ANVISA a Resolução da Diretoria Colegiada $n^{\circ}$ 9/2015, que tem como objetivo definir procedimentos e requisitos para a realização de ensaios clínicos com medicamentos.

Grande parte das pesquisas clínicas realizadas no Brasil tem como patrocinador laboratórios estrangeiros, que realizam pesquisas multicêntricas, ou seja, diversos países participam do mesmo estudo ao mesmo tempo. As informações quanto a realização de pesquisas multicêntricas é pública, está disponível a qualquer cidadão, basta verificar na plataforma da International Clinical Trials Registration, bem como no World Health Organizatin (ICTRP/WHO) entre outras, essa é uma dentre tantas exigências constante na $\mathrm{RDC} \mathrm{n}^{\circ}$ 9/2015. 
Em seu art. $4^{\circ}$ a Resolução estipula para quais situações ela não será aplicada, conforme vejamos: "Esta Resolução não é aplicável a estudos de bioequivalência e biodisponibilidade relativa, ensaio clínico com cosméticos, com produtos para saúde, com alimentos, com terapia gênica e células-tronco, devendo estes seguir regulamentações específicas". Importante ressaltar que a referida Resolução não servirá para os estudos com terapia gênica, está deverá ser disciplinada em regulamento próprio. Foi a partir de 2018 que surgiram importantes avanços na regulamentação da terapia gênica, uma vez que a cada dia emerge a necessidade de que se autorizem os estudos de terapia gênica no país.

Outra importante norma administrativa é a Resolução no 466 de 12 de dezembro de 2012 do Conselho Nacional de Saúde que também estabelecem diretrizes e normas regulamentando a pesquisa envolvendo seres humanos.

Inicialmente a Resolução traz a conceituação de termos e definições importantes para esclarecer quem é o participante da pesquisa (II.10), o patrocinador (II.11), o conceito de pesquisa (II.12), dentro outros, mas para o presente estudo é importante mencionar que no item II.8 da Resolução estabelece quem poderá ser a instituição proponente de pesquisa “organização, pública ou privada, legitimamente constituída e habilitada, à qual o pesquisador responsável está vinculado". Esse ponto será abordado mais tarde, quando será analisado o impacto da nova legislação sobre proteção de dados.

A Resolução também prescreve que a vontade do participante da pesquisa de contribuir e permanecer ou não, deve ser respeitada, por intermédio de manifestação expressa, livre e esclarecida (III.1 “a”); prever procedimentos que assegurem a confidencialidade e a privacidade dos participantes (III.2 “i”), bem como utilizar o material e os dados obtidos na pesquisa somente para a finalidade prevista no protocolo (III.2 “q”).

Ademais, a referida Resolução também traz no seu arcabouço o que deverá obrigatoriamente conter no Termo de Consentimento Livre e Esclarecido que será dado para o paciente assinar, confirmando o seu interesse em participar da pesquisa. Nesta seara é importante frisar o item IV.3 "d", em prevê a "garantia de plena liberdade ao participante da pesquisa, de recusar-se a participar ou retirar seu consentimento, em qualquer fase da pesquisa, sem penalização alguma". 
Ainda que de forma breve, algumas legislações de grande relevância para a pesquisa clínica foram suscitadas e são de extrema importância para o desenvolvimento da ciência bem como para a população em geral que muitas vezes a única solução para a manutenção da vida se dá através de novos experimentos, novos medicamentos e novas técnicas.

\section{Terapia Gênica e sua regulamentação no ordenamento jurídico brasileiro}

\subsection{Conceito de Terapia Gênica}

A história da humanidade desde meados de 1800 é marcada por movimentos que visavam aprimorar a raça humana, também conhecido como eugenia. Em 1927 a Suprema Corte dos Estados Unidos defendeu a constitucionalidade da esterilização. Mais tarde outros países passaram a utilizar mecanismos e criar leis como forma de impedir a "reprodução de pessoas com genes indesejáveis". (SANDEL, 2015, p. 79). As vítimas na época eram pessoas pobres, com algum tipo de deficiência mental e prisioneiros. A Alemanha foi além eugenia e propôs o massacre em massa de milhares de judeus, visando a seleção e exclusão da sociedade.

A partir daí emergiu a preocupação em estabelecer proteções a dignidade da pessoa humana, preservando não só a vida, mas também outros direitos como a integridade, a moradia digna, alimentação, saúde, entre outros.

Com o passar do tempo, a evolução da biotecnologia e da medicina, o desenvolvimento da outras práticas foram desenvolvidas. A capacidade humana de inovação aliada a mecanismos tecnológicos têm permitido por um lado a cura de muitas doenças e por outro o desenvolvimento de mecânismos para o aprimoramento da espécie humana. Sendo que esta última tem criado uma série de conflitos éticos, morais e jurídicos. Tais avanços têm permitido que pais deliberadamente optem por terem filhos com deficiências (SANDEL, 2015, p. 15), outros, que seus filhos já nasçam com habilidades para a prática de esportes e ainda aqueles que procuram doadoras de óvulos que possuem alto quociente de inteligência. (SANDEL, 2015, p. 16/17).

Ao passo que adentramos as novas questões suscitadas no campo da genética e do desenvolvimento de novas biotecnologias é de suma importância traçar algumas distinções, quando de um lado temos a preocupação com a saúde dos pacientes - a busca por novos 
tratamentos, medicamentos e técnicas - e por outro quando se busca através destas técnicas o seu uso equivocado como uma forma de satisfazer o mercado. A primeira situação tratando do avanço louvável da terapia gênica e a segunda tratando do melhoramento genético, traçando a diferença entre ambos para uma melhor compreensão quanto às nuances que pairam sobre tais técnicas.

Segundo Rafael Linden (2008, p. 29) Terapia Gênica (ou terapia genética) é um procedimento destinado a introduzir em um organismo, com o uso de técnicas de DNA recombinante, genes sadios para substituir, manipular ou suplementar genes inativos ou disfuncionais.

A técnica da Terapia Gênica tem como fundamento tratar pessoas doentes, que não conseguem restabelecer a saúde por outro meio. Este é um procedimento novo, que dá seus primeiros passos, uma vez que aguarda a sua regulamentação para que possam ser iniciados os estudos clínicos. Essa novidade trazida pelo desenvolvimentos das biotecnologias tem gerado ampla expectativa, como uma possibilidade de cura para doenças que ainda não possuem tratamento eficaz.

Quando o tema é abordado ele geralmente suscita quationamentos, por ser algo novo e portanto desconhecido da maioria das pessoas, e porque muitas vezes é confundido com o melhoramento genético.

Porém o melhoramento genético tem como objetivo tornar a raça humana melhor, conforme vejamos os ensinamos de Michael Sandel:

\footnotetext{
"As descobertas da genética nos apresenta a um só tempo uma promessa e um dilema. A promessa é que em breve seremos capazes de tratar e previnir uma série de doenças debilitantes. O dilema é que nosso recém-descoberto conhecimento genético também pode permitir a manipulação de nossa própria natureza - para melhorar nossos músculos, nossa memória e nosso humor; para escolher o sexo, a altura e outras caracteristicas genéticas de nossos filhos, para nos tornar "melhores do que a encomenda".
}

A preocupação é ainda maior quando esse melhoramento não diga respeito a decisão individuais sobre o próprio corpo, mas quando terceiro decide como o outro será, como por exemplo os pais que decidem como querem seus filhos, e a intervenção genética se dá no "nível da linha germinal, que concentram nos óvulos, espermatozóides ou embriões, afetando as gerações subsequentes”. (SANDEL, 2015, p. 21) 
Ao modificar a carga genética na linha germinativa todas as demais gerações serão afetadas, e a preocupação é também por não se ter certeza que tal técnica não possa acarretar problemas em outras células. Os estudos ainda precisam avançar nesse sentido para esclarecer quais serão os possíveis efeitos colaterais nessas situações, porque caso contrário, a alteração da raça pode não ser apenas para melhorar, mas vir a causar males ainda desconhecidos nas próximas gerações .

Habermas (2010, p. 18) propõe o questionamento sobre a autonomia do indivíduo frente aos avanços desenvolvidos no campo da engenharia genética:

"Devemos considerar a possibilidade, categoricamente nova, de intervir no genoma humano como um aumento de liberdade, que precisa ser normativamente regulamentado, ou como a autopermissão para transformações que dependem de preferências e que não precisam de nenhuma autolimitação? Somente quando essa questão fundamental for resolvida em favor da primeira alternativa é que poderão discutir os limites de uma eugenia negativa e inequivocamente voltada a eliminação de males".

A discussão suscitada diz respeito a liberdade do indivíduo, que nada mais é que a sua autonomia frente às diversas escolhas pessoais que cada indivíduo pode fazer em relação a própria vida, será que de alguma forma será afetada?

Até hoje, o pensamento secular da modernidade europeia pôde, tanto quanto a crença religiosa, partir do princípio de que a constituição dos recémnascidos e, por conseguinte, as condições orgânicas iniciais para sua futura história de vida escapavam da programação e da manipulação intencional feitas por terceiros. (HABERMAS, 2010, p.18/19)

Nesse momento outra questão tão relevante quanto às demais terá de ser analisadas, a conduta do terceiro que propõe o melhoramento genético ou outra situação semelhante, pode ter sua conduta universalizavel ou ela visa atingir um resultado, e estaríamos diante da ética funcionalista.

O progresso das ciências biológicas e o desenvolvimento das biotecnologias ampliam não apenas as possibilidades de ação já conhecidas, mas também possibilitam um novo tipo de intervenção. O que antes era 'dado' como natureza orgânica e podia quando muito ser 'cultivado', move-se atualmente no campo da intervenção orientada para um objetivo. (HABERMAS, 2010, p. 17) 
O desenvolvimento da tecnologia no campo genético tem grande relevância para cura de pacientes em situações graves, mas por outro lado pode de forma definitiva alterar os rumos da vida de uma pessoa e de todas as demais gerações. E essa determinação feita por terceiro, que influencia na autonomia do indivíduo, tem grande relevância para o direito, emergindo a preocupação quanto a produção de leis que consigam regulamentar tais questões.

A preocupação paira justamente no fato da interferência de um terceiro, e este decidindo sobre a vida do outro. As características e habilidades das pessoas não são mais atribuídas ao acaso e sim em escolhas. A criança fruto da projeção dos pais já nasce com uma projeção de futuro, a autonomia das pessoas é relativizada, ela terá como "responsabilidade" satisfazer anseios que não são seus? Nesse sentido os filhos poderão responsabilizar os pais pela escolha genética? Vários são os questionamentos que surgem se é possível que se utilize a técnica de modificação genética para o melhoramento genético, mas não antes de se propor um amplo debate transdisciplinar possibilitando que verifique quais serão os efeitos desta autorização.

Como forma de ilustrar a referida preocupação, na última semana de novembro de 2018, tema foi pauta nos noticiários nacionais e internacionais. O caso tratado na introdução e que faz referência a reportagem diz respeito ao cientista e professor He Jiankui, o experimento realizado por ele foi a partir da remoção de uma proteína do DNA dos embriões de duas gêmeas, o intuito do cientista foi de impedir que elas contraíssem o vírus de HIV. Segundo a matéria as crianças nasceram saudáveis e o experimento realizado não foi de conhecimento da Southern Universityof Science and Technology, em Shenzen, no qual o cientista é pesquisador. Ele manifestou-se dizendo ter sido alvo de duras críticas, o que consequeência motivou forte debate ético.

Os avanços tecnológicos têm sido vistos e sentidos por todos, as mais diversas áreas de conhecimento têm de alguma forma sido impactada com a crescente expansão tecnológica da última década, mas que deverá ser enfrentada pelos juristas, legisladores, e demais profissionais, afim de se debater tal temática, assim como os profissionais da área médica e afins.

\subsection{Previsão no ordenamento jurídico brasileiro}

A Agência Nacional de Vigilância Sanitária inseriu a regulamentação da Terapia 
Gênica no quadriênio de 2017-2019, que consta no item 10.4 denominada de produtos de terapias avançadas: terapia celular avançada, engenharia tecidual e terapia gênica (GSTCO), que está inserida no grupo sangue, tecidos e órgãos.

A Anvisa aprovou recentemente a Resolução da Diretoria Colegiada nº 260/2018, em que prevê as regras para a realização de ensaios clínicos com produtos de terapia avançada. A referida resolução é um importante passo na regulamentação para a realização de ensaios clínicos utilizando a técnica de terapia gênica. No art. 4, inciso XXXVII estabelece o conceito de Produtos de Terapias Avanças, como sendo os produtos de terapia celular avançada, os produtos de engenharia tecidual e os produtos de terapia gênica. A Terapia gênica é considerada Produto de Terapia Avançada classe II, que é submetido à manipulação extensa, junto do produto de engenharia tecidual.

A Terapia Gênica é reflexo de um importante avanço da genética, mas que ainda está sendo regulamentada, a passos lentos, mas espera-se que embasada em amplo debate quanto aos seus benefícios e possíveis riscos.

\section{A entrada em vigor da Lei $n^{\circ}$ 13.709/2018 (LGPD) e os reflexos no campo da Pesquisa Clínica}

\subsection{Lei Geral de Proteção de Dados - Lei n 13.709/2018}

Uma nova lei foi aprovada no direito pátrio, é a Lei Geral de Proteção de Dados (LGPD) $n^{\circ}$. 13.709/2018. Ela dispõe sobre o tratamento de dados pessoas, por pessoas naturais e jurídicas tanto de direito público quanto privado. A inovação vai além da proteção dos dados como nome, contato telefônico, endereço residencial, correio eletrônico, etc. A preocupação com os direitos de intimidade, vida privada e liberdade da pessoa natural também abarca aqueles dados ditos sensíveis que compreendem a origem racial ou ético, convicção religiosa, opinião pública, filiação a organização de caráter religiosos, filosófico ou políticos, mas principalmente aqueles dados referente a saúde ou à vida sexual, dado genético ou biométrico.dados que digam respeito a saúde (prontuários e laudos médicos) mas também aqueles que dizem respeito ao código genético.

A preocupação suscitada pela nova legislação que entrará em vigor apenas em agosto de 2020 já requer uma mudança de conduta daqueles que possuem bancos de dados de forma ampla, como por exemplo as agências bancárias, empresas de telefonia, SERASA e 
outros gestores de bancos cadastrais, mas a preocupação do presente ensaio visa analisar os reflexos da LGPD no que diz respeito aos bancos de dados dos hospitais, principalmente aqueles que participam de pesquisas internacionais com genética, justamente pela proteção que a nova lei traz para essas situações.

Umas das mudanças radicais implementadas pela nova legislação é a aplicação de multas em valores elevadíssimos, ela vem com um caráter essencialmente sancionatório. O lapso temporal entre a aprovação da lei (ano 2018) até o início da sua vigência (ano 2020) é o período de adaptação concedido a todos aqueles órgãos que armazenam, transferem, realizam tratamento de dados e etc. a adequarem-se a nova legislação sob pena de serem responsabilizados civilmente.

O ano de 2018 encerrou com a aprovação de duas importantes legislações de proteção de dados. A Lei no 13.709 de 14 de agosto de 2018, também conhecida como Lei Geral De Proteção de Dados Pessoais (LGPD), que dispõe sobre o tratamento de dados pessoais, incluindo os digitais, tanto por pessoas naturais quanto jurídicas, no intuito de preservar os direitos fundamentais de liberdade e de privacidade. Foi instituída também a Lei 13.787/2018, que dispõe sobre a digitalização e utilização de sistemas informatizados para guarda, o armazenamento e manuseio de prontuários médicos.

Como forma de permitir uma maior interpretação da legislação posta em análise, é importante trazer alguns conceitos que são recorrentes em diversos de seus artigos, como é o caso da expressão tratamento que segundo a própria lei conceitua, como toda operação realizada com dados pessoais, como as que se referem à coleta, produção, recepção, classificação, utilização, acesso, reprodução, transmissão, distribuição, processamento, arquivamento, armazenamento, eliminação, avaliação ou controle da informação, modificação, comunicação, transferência, difusão ou extração. ${ }^{1}$

No arcabouço do art. $6^{\circ}$ elenca os princípios pelas quais a atividade de tratamento de dados deve observar, quais sejam: a boa fé, a finalidade, adequação, necessidade, livre acesso, qualidade de dados, transparência,segurança, prevenção, não discriminação e por fim, responsabilidade e prestação de contas.

A referida lei vem com o intuito de preservar e proteger os cidadãos da divulgação, roubo ou vazamento de seus dados pessoais. Contudo embora tenha sido 
pensada para restringir ao máximo a violação de tais dados, por outro lado acabou por engessar e em alguma medida criar empecilhos no campo da saúde, conforme vejamos a seguir.

\subsection{Reflexos da LGPD nas Pesquisas Clínicas no Brasil}

A Lei Geral de Proteção de Dados entrará em vigor em agosto de 2020, mas já está ensejando amplos debates, mas mais diversas áreas, por ser justamente uma lei que tem como fundamento a proteção geral dos dados dos individuos, obrigando que todos adaptem-se com as novas mudanças. Mas o objeto do presente estudo diz respeito das alterações no campo da pesquisa clínica.

A referida lei não esta em consonância em alguns pontos com a Resolução $n^{\circ}$ $466 / 2012$ do CNS, sendo que esta traz no que o porponente da pesquisa pode ser “organização, pública ou privada, legitimamente constituida e habilitada, à qual o pesquisador responsável está vinculado" (II.8), já a LGPD no art. 5, inciso XVIII, que o órgão de pesquisa, "órgão ou entidade da administarção pública direta ou indireta ou pessoa jurídica de direito privado sem fins lucrativos legalmente constituída sob as leis brasileiras, [...]. Como já mencionado anteriormente o Brasil conta com patrocinadores estrangeiros, podendo inviabilizar a participação dos laboratórios e o tratamento de dados por eles, uma vez que possuem fins lucrativos.

Da mesma forma a Resolução estabelece (III.1, "a") que o participante de pesquisa poderá desistir a qualquer tempo de participar da pesquisa, a LGPD prevê no art. 16 que no término do tratamento os dados pessoais do participante serão eliminados. Nesse ponto vejo que é de suma importância porque todos os dados que iriam fazer parte da pesquisa deverão ser eliminados, não só quando o paciente decide não querer mais fazer parte da pesquisa, mas também ao término do seu tratamento. Ademais, com a nova legislação o paciente deverá autorizar a transferência de seus dados, o que se vê como uma ampla proteção da intimidade dos indíviduos, mas que por outro lado poderá acabar inviabilizando as pesquisas, por se tratar de um número consideravel de pacientes, mas que também terá de fazer com os dados já coletados antes mesmo da criação da legislação, que se não inviabilizar por completo, pelo menos irá gerar grandes dificuldades e gastos para os hospitais.

Da mesma forma a LGPD traz em seu arcabouço a previsão de anonimização dos 
dados, o que fará com que os hospitais tenham esses dados ainda mais protegidos e criando códigos para a sua identificação. Mas que terão que investir em pessoas qualificadas e que terão papel único e exclusivamente para fazer o tratamento, armazenamento e transferência de dados

Além disso a LGPD criou regras sobre a limitação ao compartilhamento e comunicação dos dados, com previsão no $\S 3^{\circ}$ e $\S 4^{\circ}$ do art. 11 para situações com cunho econômico, outra importante reflexão nesse ponto, que embora num primeiro momento as pesquisas clínicas sejam desenvolvidas visando a cura dos pacientes, muitas vezes isso se dá através da testagem de um novo medicamento, que no futuro continuará tratando o paciente e participante da pesquisa, mas este medicamento vai para o mercado de consumo, terá ao final caráter econômico. Esta e diversas questões tem despertado o estudo e a busca de uma solução para as situações que futuramente poderão gerar conflitos.

\section{CONCLUSÃO}

Ambos os temas de grande relevância ao direito brasileiro, sejam as novas tecnologias sendo desenvolvidas no campo da genética, como a pesquisa clínica de terapia gênica e do melhoramento genética, bem como a preocupação com os pacientes participantes destas pesquisas porque que são titular de um direito geral de liberdade - que lhe seja garantido um "futuro aberto" de que cada um seja responsável por tomar as decisões da própria vida - e de intimidade - pela proteção dos dados pessoais-, ambas as situações requerem uma atenção especial e exigem dos profissionais, sejam médicos, biólogos, e outras áreas afins, mas mais ainda dos juristas, legisladores e aplicadores do direito, que tão rápido quanto a inovação são os conflitos gerados, seja por legislações conflitantes ou pela ausência delas.

Em vista do interesse da ciência em desenvolver novas técnicas para proteção da saúde, desenvolvimento de novos medicamentos e tratamentos podem e devem ser estimulados, mas precisa-se que se tenha cautela, por tratar da vida humana.

Os avanços de terapia gênica já estão sendo debatidos pela Anvisa, está na pauta do anuário de 2017-2020, a legislação para possivelmente autorizar a pesquisa clínica. No caso do melhoramento genético, em que se pretende distorcer os fundamentos da ciência de cura e aproximar-se de uma ideia de eugenia, de seleção da raça humana, a partir do 
melhoramento na fase germinativa em que se estará alterando a raça humana, está ainda não está em pauta. E que o momento que ingressar na pauta de discussão, seja para frear de antemão tal possibilidade.

A proteção de dados já vem sendo pensada, tanto que temos a Lei do Marco Civil da Internet (Lei $\mathrm{n}^{\circ} 12.965 / 2014$ ), a Lei $\mathrm{n}^{\circ}$ 13.787/2018 que prevê sobre a digitalização e guarda de prontuários médicos, dentre outras, mas que uma grande inovação na seara jurídica é a entrada em vigor de uma nova Lei Geral de Proteção de Dados que dispõe sobre a cobrança de altíssimos valores a título de multa para as empresas públicas e privadas que não se adaptarem as novas regras ou se as descumprirem. Essa talvez seja uma das maiores repercussões, porque o caráter punitivo da lei vem com toda força nesse novo ano, como forma de inibir que a violação de dados ocorra e fique impune. Desta forma, o tempo entre aprovação da legislação até a sua entrada em vigor, é uma oportunidade tanto do setor público quanto privado de adequação.

Os participantes de pesquisa, bem como uma forma geral, os cidadãos não podem ficar a mercê das novas tecnologias sem regulamentação, os direitos que lhes são garantidos deverão ser preservados, mas desde que também sejam observadas as necessidades e manutenção das pesquisas clínicas, uma vez que resguarda na sua essência algo que é mais importante para o cidadão que a privacidade é a vida, que muitas vezes só lhe é garantida através de novos medicamentos e novos procedimentos.

\section{REFERÊNCIAS}

ARENDT, Hannah. A condição humana.12 edição. Rio de Janeiro: Forense Universitária, 2016.

. Eichmann em Jerusalém: Um relato sobre a banalidade do mal. São Paulo: Companhia das letras, 1999.

DOMINGUES, Ivan. Biotecnologias e regulações: desafios contemporâneos. Belo Horizonte:Editora UFMG,2018.

FERRY, Luc. A nova ordem ecológica: $A$ árvore, o animal e o homem. Rio de Janeiro, Difel, 2009. 
- VINCENT, Jean-Didier. O que é Ser Humano. Sobre os princípios fundamentais da filosofia e da biologia. Petrópolis, Editora Vozes, 2011.

- A revolução transumanista. Tradução de Éric R. R. Heneault. -Barueri, SP:Manole, 2018.

FONSECA, Lilian Simone Godoy. Biotecnologias: novos desafios e novas responsabilidades à luz da ética de Hans Jonas. Belo Horizonte: Editora UFMG, 2015.

HABERMAS, Jürgen. A ética da discussão e a questão da verdade. São Paulo: Martins Fontes, 2007.

. O futuro da natureza humana. São Paulo: Martins Fontes, 2010.

LINDEN, Rafael. Genes contra doenças: terapia gênica: uma nova era na genética. Rio de Janeiro: Vieira \& Lent, 2008.

NUSSBAUM, Martha. Fronteiras da Justiça. Deficiência, nacionalidade, pertencimento à espécie. São Paulo: Martins Fontes, 2013.

PEREIRA, Paula Moura Francesconi de Lemos. Responsabilidade civil nos ensaios clínicos. Indaiatuba, SP:Editora Foco, 2019.

SANDEL, Michael J. Contra a Perfeição: Ética na era da engenharia genética. Tradução: Ana Carolina Mesquita. 2ªe ed. Rio de Janeiro: Civilização Brasileira, 2015. SINGER, Peter. Ética Prática. São Paulo: Martins Fontes, 2002. 